\title{
Bioactive Compound from Extract Filtrat Streptomyces sp.Sp1. as Biocontrol of Vibriosis on Larvae of Macrobrachium rosenbergii shrimps
}

\author{
R Kawuri*, IBG Darmayasa \\ Department of Biology, Faculty of Mathematics and Natural Sciences, Udayana University, Kampus Bukit Jimbaran, Bali, Indonesia
}

ARTICLE INFO

Article history:

Received July 9, 2017

Received in revised form December 9, 2018

Accepted December 16, 2018

\section{KEYWORDS:}

Macrobrachium rosenbergii,

shrimp,

Streptomyces sp.Sp1,

bioactive compound,

biocontrol

\begin{abstract}
Production of Macrobrachium rosenbergii shrimp was limited by vibriosis disease. Streptomyces can be used as an alternative control of vibriosis which is caused by Vibrio anguillarum. Aplication of Streptomyces sp.1 culture could give significant different impacts $(\mathbf{p}<\mathbf{0 . 0 5})$ on the percentage of survival $(\mathrm{SR})$ of shrimp larvae that had been infected by $V$. anguillarum compared to the control. This study was conducted to identify and determine bioactive compound of Streptomyces sp.1. The presence of bioactive compound was confirmed by gas chromatographymass spectrometry (GC-MS) analysis. Identification of Streptomyces sp.1 by 16S rRNA partial gene sequencing method. Streptomyces sp.1 was identified to be Streptomyces sp.Sp1. There were 35 chemical compounds identified, the chemical compounds which have antimicrobial properties identified in the $n$ butanol extract of Streptomyces sp.Sp1 are 3-Hexanone, 2-methyl (43\%), n Butyl ether (19\%) Nonane (CAS) n-Nonane (5.6\%), Decane (CAS) n-Decane (3.2\%), Hexacosane (CAS) n-Hexacosane (1.9\%), Tetracontane (1.3\%), Heneicosane $(\mathbf{1 . 9 \%})$, Hexadeconoic acid, methyl ester $(0.3 \%)$, Butane, $1,1-$ dibutoxy $(0.3 \%)$, and Limonene (0.3\%). Benzeneacetic acid, 3-methoxy-.alpha.,4-bis[(tri (0.3\%). These results suggested that Streptomyces $\mathbf{s p . S p 1 ~ h a d ~ g o o d ~ g e n e r a l ~ a n t i m i c r o b a ~ a c t i v i t y ~}$ and might have potential biocontrol antagonist Vibrio anguillarum.
\end{abstract}

\section{Introduction}

Giant prawns are one of the original Indonesian freshwater shrimp. The introduction of this commodity for aquaculture began by the Department of Marine and Fisheries in 2001 as a superior alternative commodity. Giant shrimp is very potential to be used as an alternative commodity because it has a large body size compared to other types of shrimp farming and has high economic value in the market (Priyono et al. 2011).

Based on the results of the survey conducted (2017), one of the efforts to seed giant prawn larvae in Bali is carried out by the Bali Province Marine and Fisheries Hatchery Unit in the Klungkung Bali. The amount of ready-stock shrimp production produced by the UPT is generally very volatile. This is influenced by environmental and microbiological

\footnotetext{
* Corresponding Author

E-mail Address: microbiologylaboratory@yahoo.com
}

conditions of the pond, especially the presence of pathogenic bacteria that cause disease.

Vibriosis in addition to infecting shrimp in aquaculture ponds can also infect shrimp larvae in hatcheries. Infection at the seed level is very dangerous because it can cause high seed mortality and can be a source of entry of pathogens into the pond (Patang 2012). Oanh et al. (2008) also reported Vibrio infection in Macrobrachium rosenbergii larvae and postlarvae causing significant mortality for 48 hours of testing. Therefore production of $M$. rosenbergii shrimp was limited by vibriosis disease. Streptomyces can be used as an alternative control of vibriosis which is caused by Vibrio anguillarum. As our previous research showed that application of Streptomyces sp.1 culture give significant different impacts $(p<0.05)$ on the percentage of survival (SR) of shrimp larvae that had been infected by $V$. anguillarum compared to the control. Treatment of Streptomyces sp. 1 culture could also significantly $(p<0.05)$ reduce the total population of Vibrio on the 
maintenance media compared to the control (Bintari et al. 2017).

Most Streptomyces spp. can produce antibiotic such as cephamycin, chloramphenicol, kanamycin, tetracycline, spectinomycin, streptomycin, clavulanic acid, and monensin (Barrios et al. 2003) Lowicki and Huczynski (2013) showed monensin that isolated from $S$. cinnamonensis can inhibit the growth of bacteria genus Micrococcus, Bacillus, and Staphylococcus.

Gas chromatography-mass spectrometry (GCMS) analyses have been developed for the analysis and characterization of active compounds from micro-organisms. This study aimed to identify Streptomyces sp.1 with 16S rRNA and determine the GC-MS analysis of the $n$ butanol extracts of bioactive compound of Streptomyces sp.1.

\section{Materials and Methods}

Streptomyces sp.1 (collection of Microbiology Lab. FMIPA Unud, Figure 1), molecular identification using 16S rRNA with primers 63f (5'-CAG GCC TAA CAC ATG CAA GTC-3') and primer reverse 1387r (5'GGG CGG WGT GTA CAA GGC-3') was conducted in the Laboratory of Microbiology, Bogor Agricultural Institute (Institut Pertanian Bogor/IPB).

\subsection{Isolation of Genomic DNA}

Rejuvenation of bacterial isolates was done by using Yeast Salt Agar (ISP6) media and the cultures were incubated at room temperature for four days. Five colony circles (diameter $5 \mathrm{~mm}$ ) were added to Yeast Salt Broth (ISP7) media and incubated in an incubator shaker at a temperature of $25^{\circ} \mathrm{C}$ for four days. Isolation of DNA was done by CTAB method according to Marchesi et al. (1988).

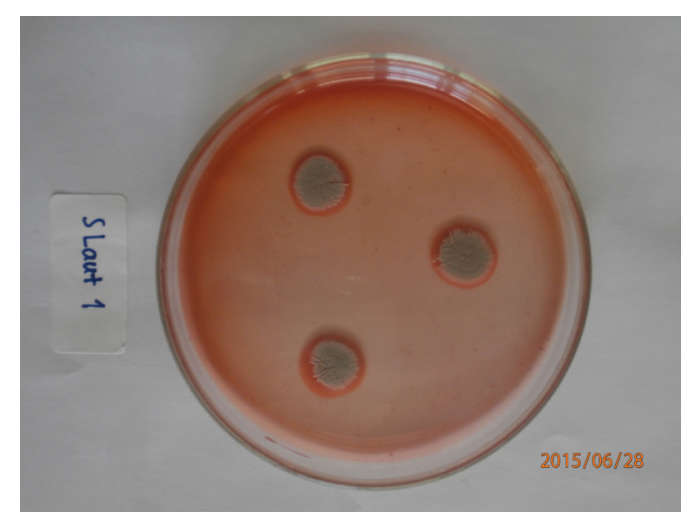

Figure 1. The colony of Streptomyces sp.1 on YEMA media (Bintari et al. 2017)

\subsection{DNA Amplification by PCR}

16S rRNA gene was amplified by Polymerase Chain Reaction machines (Perkin Elmer GeneAmp PCR system 2400, Germany) using specific primers of prokaryotic actinomycetes, namely 63f (5'-CAG GCC TAA CAC ATG CAA GTC-3'), and primer reverse $1387 \mathrm{r}$ (5'-GGG CGG WGT GTA CAA GGC-3'). The composition of the PCR reaction consisting of Taq DNA polymerase enzyme La $0.5 \mathrm{ml}, 25 \mathrm{ml}$ 2X GC buffer, dNTP mixture $8 \mathrm{ml}$, 20f primer (10 pmol) $1.5 \mu \mathrm{l}, 1387 \mathrm{r}$ primer (10 pmol) $1.5 \mu$, ddH2O 9.5, and $4 \mu$ DNA template. PCR conditions used are predenaturation $\left(94^{\circ} \mathrm{C}, 5 \mathrm{~min}\right)$, denaturation $\left(94^{\circ} \mathrm{C}, 1 \mathrm{~min}\right)$, annealing $\left(57^{\circ} \mathrm{C}, 1 \mathrm{~min}\right)$, elongation $\left(72^{\circ} \mathrm{C}, 1\right.$ minute and 10 seconds), and the post-PCR $\left(72^{\circ} \mathrm{C}, 7 \mathrm{~min}\right)$ with the number of cycles of 30 cycles. The separation of DNA PCR products is done on a mini-gel electrophoresis machine using $1 \%$ agarose on 75 volt power supply voltage for 45 minutes. Visualization of DNA was done over the UV transilluminator using Ethidium Bromide (EtBr) dye.

\subsection{DNA Sequence and Alignment}

The amplified Deoxyribose Nucleic Acid (DNA) was partially sequenced to determine the nucleotide sequences using the services of PT Macrogen, Korea. The nucleotide sequences, as the result of the sequencing process, would then be aligned with the GeneBank data using BLAST-N program (Basic Local Alignment Search Tool-Nucleotides) from the NCBI website (National Center for Biotechnology Information).

\subsection{Preparation of Streptomyces sp.1 Extract}

Streptomyces sp.1 was grown for five days at Yeast Malt Agar (YEMA) media and incubated at $28^{\circ} \mathrm{C} \pm$ $2^{\circ} \mathrm{C}$, then taken using cork borer (diameter of $5 \mathrm{~mm}$ ) by 5 pieces and put in an erlenmeyer $(250 \mathrm{ml})$ filled with $50 \mathrm{ml}$ Yeast Malt Extract Broth (1\% malt extract, $0.4 \%$ dextrose, $0.4 \%$ yeast extract, $2 \%$ agar; $\mathrm{pH} 7.0$ ) media. Then it was incubated on a incubator shaker at temperature of $28^{\circ} \mathrm{C} \pm 2^{\circ} \mathrm{C}$ at $125 \mathrm{rpm}$ speed for 14 days. Filtrate from culture was then collected, followed by centrifugation at $11,000 \mathrm{rpm}$ speed for 15 minutes and was filtered using filter paper 0.45 $\mu \mathrm{m}$. Filtrate partition was done by pouring the filtrate into a 1 litre separation bottle and then $\mathrm{n}$ butanol solvent was added at ratio of $1: 1(\mathrm{v} / \mathrm{v})$, followed by evaporation to separate $\mathrm{n}$ butanol with filtrate using evaporator machine (Buchi Rotavapor R-210, Japan). Then it was homogenized and left undisturbed for 24 
hours to separate between water phases and ethyl acetate phase. Each of these phases (water and ethyl acetate phase) was separated by separating funnel and then $\mathrm{n}$ butanol phase was evaporated with an evaporator machine at a temperature of $40^{\circ} \mathrm{C}$ (Buchi Rotavapor R-210, Japan) to obtain an extract used for further testing.

\subsection{Purification of Active Compound Extract Streptomyces sp.1}

The purification of active compounds were separated by thin layer chromatography (TLC) method (Sharon et al. 2013). The extract was spotted on a TLC plate (silica gelplat Merck 60 F254) developed with a mixture of chloroform-ethyl acetate-acetic acid $(7: 3: 1, v / v)$ and node visualized under UV light $\lambda 254 \mathrm{~nm}$ and $\lambda 365 \mathrm{~nm}$. Each band were scrapped out separately and collected in different vials. Then the each band compounds were checked again for bioactive metabolites by agar well diffusion method. Testing is done by testing the activity of the extract of Streptomyces sp.1 against $V$. anguillarum. Petri dish that already contains $10 \mathrm{ml}$ of media NA and $200 \mathrm{ml}$ of the suspension of against $V$. anguillarum allowed to solidify and after solid diffusion wells were made using a cork borer.

\subsection{GC-MS Analysis}

Identification of active compounds of Streptomyces sp.1 that had bactericidal activity against Vibrio anguillarum causing vibiosis in Macrobrachium rosenbergii shrimp was identified using gas chromatography-mass spectroscopy (GC-MS). A snapshot of most active and a relatively pure fraction was analyzed by gas chromatography-mass spectrometry. Through suitability of molecular weight and fragmentation pattern of the isolated compounds with the compounds in the library (WILEY or NIST) in the GC-MS system then isolated compounds could be known of the name, formula and molecular structure (Gopalakrishnan and Vadivel 2011). Gas chromatography-mass spectroscopy test conducted at the Joint Laboratory of the Faculty of Mathematics and Natural Sciences University of Udayana, Badung, Bali. GC-MS tool used was GCMS-QP2010 Ultra SHIMADZU. Column temperature was programmed between $80^{\circ} \mathrm{C}$ and $250^{\circ} \mathrm{C}$ at a rate of $1: 18 \mathrm{ml} / \mathrm{min}$. The temperatures in the injector and detector were respectively $250^{\circ} \mathrm{C}$ and $220^{\circ} \mathrm{C}$.

\section{Results}

\subsection{Molecular Identification of Streptomyces sp. 1 using 16S rRNA}

Genome amplification of bacterial samples using PCR with primers $63 \mathrm{~F}$ and $1387 \mathrm{r}$ produced DNA fragments measuring approximately $1300 \mathrm{bp}$ (Figure 2 ). The results of the gene sequence alignments of 16S rRNA isolates sp. 1 to the data available at NCBI was available in Table 1, and Phylogenetic tree construction of Streptomyces sp. 1 was showed in Figure 3. Based on molecular identification, the Streptomyces sp.1 can be identified as Streptomyces sp.Sp1.

\subsection{Purification of Active Compound Extract Streptomyces sp.1}

The result of the extract fractionation using a hexane solvent, Ethyl acetate and $\mathrm{n}$ butanol, 8 fractions were found. Based on Retention Fraction (RF) value, it was found 4 fraction (Table 2). To the four active compounds, antagonist test was conducted with pathogen $V$. anguillarum. The result showed that RF mixture (RFG1, RFG2, RFG3, and RFG4) has the clear zone even it has inhitory zone $22 \mathrm{~mm}$ (Table 3 and Figure 4) and then analyzed for the compounds by using GCMS as indicated on Table 4 and Figure 5.

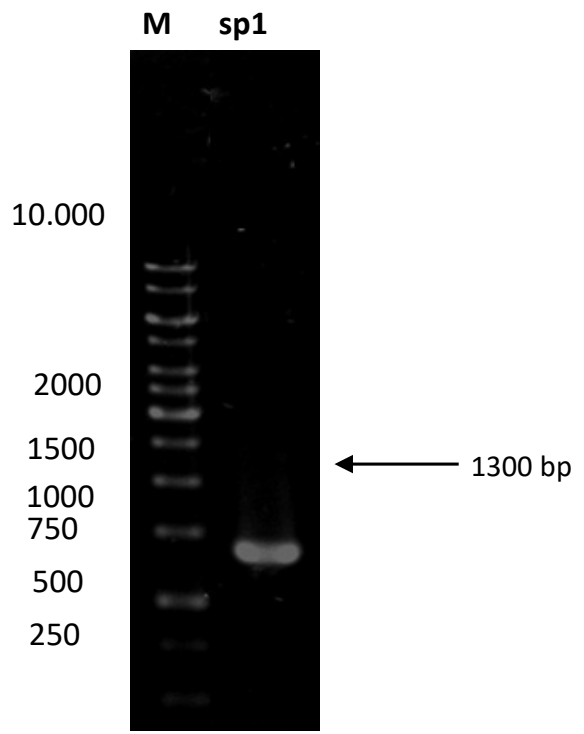

Figure 2. PCR amplification of the gene 16S rRNA with primers $63 \mathrm{~F}$ and $1,387 \mathrm{r}$ primer; $\mathrm{M}=$ marker 1 $\mathrm{Kb}$ ladder; $\mathrm{sp} 1=\mathrm{PCR}$ product samples of the bacterium 
Table 1. The results of the gene sequence alignments of 16S rRNA isolates sp.1 to the data available at NCBI (BLASTN)

\begin{tabular}{|c|c|c|c|c|c|c|}
\hline Description & Max score & Total score & Quary cover & E value & Identity & Acces number \\
\hline $\begin{array}{l}\text { Streptomyces sp. LCJ8A 16S ribosomal } \\
\text { RNA gene, partial sequence }\end{array}$ & 2,289 & 2,289 & 100 & 0.0 & 99 & KU870433.1 \\
\hline $\begin{array}{l}\text { Streptomyces djakartensis strain TTIO5.3 } \\
16 S \text { ribosomal RNA gene, partial } \\
\text { sequence }\end{array}$ & 2,289 & 2,289 & 100 & 0.0 & 99 & KT726172.1 \\
\hline $\begin{array}{l}\text { Streptomyces rochei strain H3-1 16S } \\
\text { ribosomal RNA gene, partial sequence }\end{array}$ & 2,289 & 2,289 & 100 & 0.0 & 99 & KR023965.1 \\
\hline $\begin{array}{l}\text { Streptomyces enissocaesilis strain SAS05 } \\
16 \text { S ribosomal RNA gene, partial } \\
\text { sequence }\end{array}$ & 2,289 & 2,289 & 100 & 0.0 & 99 & КР986572.1 \\
\hline $\begin{array}{l}\text { Streptomyces minutiscleroticus strain } \\
\text { KMF-2 16S ribosomal RNA gene, } \\
\text { partial sequence }\end{array}$ & 2,289 & 2,289 & 100 & 0.0 & 99 & KJ020685.1 \\
\hline
\end{tabular}

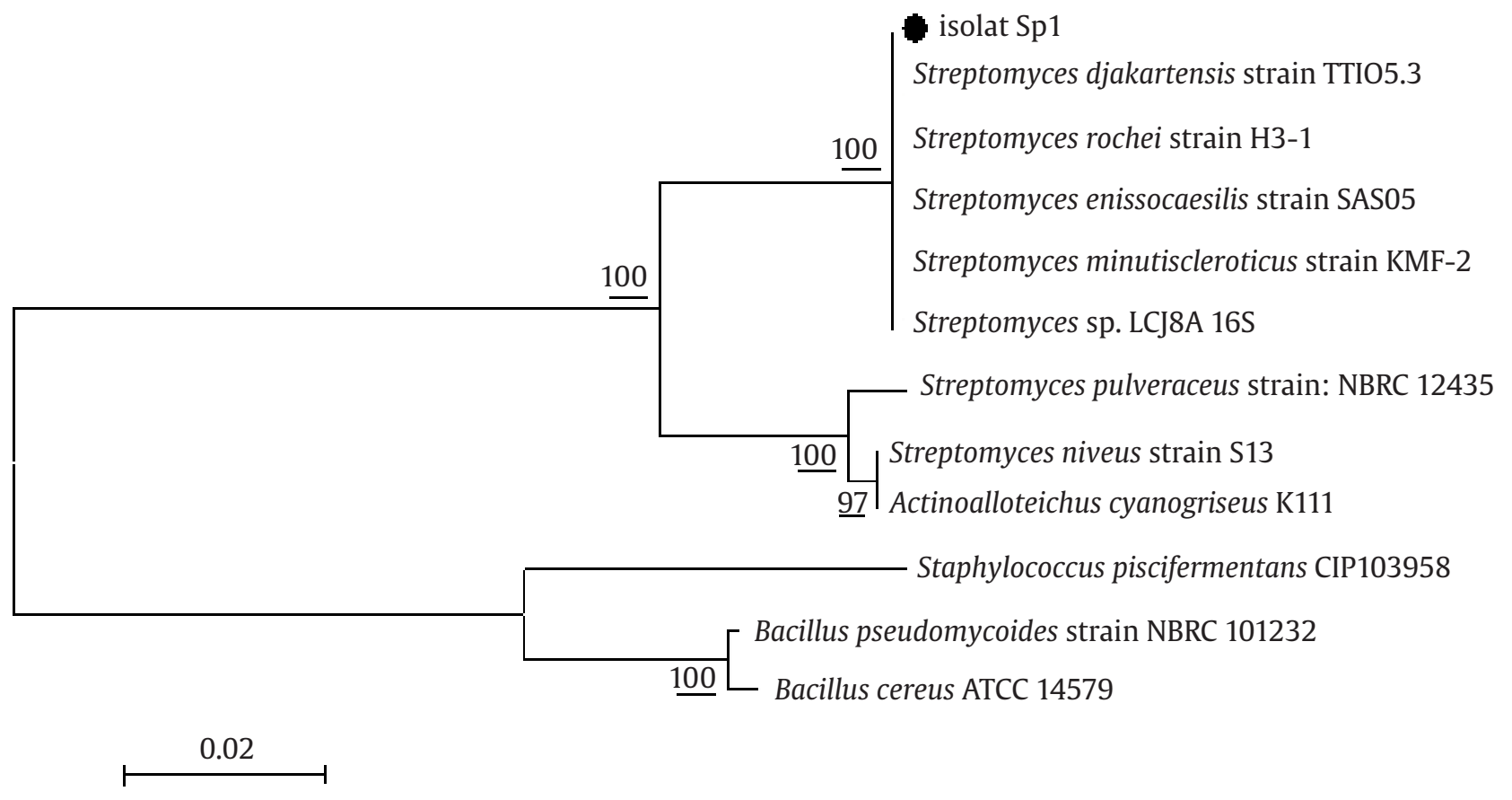

Figure 3. A phylogenetic tree that illustrates how close isolate Sp.1 against other bacteria in one clade or another clade (outer group). The construction is based on neighbor-joining tree method with bootstrap value of $1,000 x$ repetition

Table 2. Retention fraction (RF) Value of extract filtrat Streptomyces sp.Sp1

\begin{tabular}{cc}
\hline Fraction & RF value \\
\hline 1 & 0.97 \\
2 & 0.97 \\
3 & 0.93 \\
4 & 0.87 \\
5 & 0.87 \\
6 & 0.87 \\
7 & 0.98 \\
8 & 0.98 \\
\hline
\end{tabular}

Table 3. The antagonist test of the active compound of Streptomyces sp.Sp1 againts V. anguillarum

\begin{tabular}{lc}
\hline Active compound & Inhibitory (mm) \\
\hline RFG1 & 7 \\
RFG2 & 24 \\
RFG3 & 20 \\
RFG4 & 19 \\
RF mixture (RF1, RF2, RF3, RF4) & 22 \\
\hline
\end{tabular}




\subsection{GC-MS Analysis}

Gas chromatogram analysis results showed 35 peaks and each peak was identified more with mass spectroscopy in which each compound had a specific mass fragmentation pattern (Figure 5 and Table 4). Compounds identification at each peak was made by
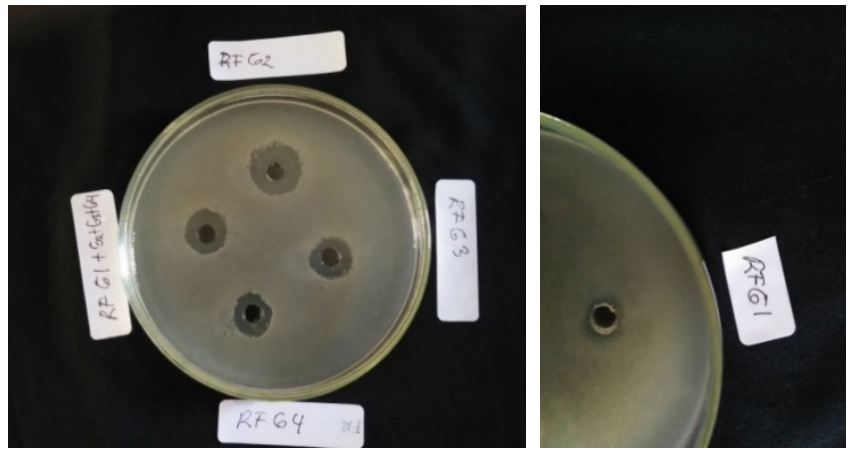

Figure 4. Antagonist test active compound with pathogen V. anguillarum comparing the mass spectrum of each peak in the mass spectrum of compounds that had been known and programmed in the data base of GC-MS. Eleven active compound have antimicrobial activities (Table 5), Spectrum and structure of the 11 antimicrobial compounds were presented on Figure 6 and Figure 7.

\section{Discussion}

After the phylogenetic- and the 16S rRNA gene sequence analyses, it is known that the strain with a significant antimicrobial capability was recognized as Streptomyces sp.Sp1. As one of the most reliable methods, a number of researchers commonly applied the Gas chromatography-mass spectrometry (GCMS) to characterize the components of volatile compounds ${ }^{6}$. Through this technique it is identified that the extract of Streptomyces sp.Sp1 have 35 major peaks with different retention time.

Table 4. Components detected in the $\mathrm{n}$ butanol extract of Streptomyces sp.Sp1

\begin{tabular}{llcc}
\hline Compound name & Molecular formula & Molecule wight & Peak area (\%) \\
\hline 3-Hexanone, 2-methyl & C7H14O & 43 & 43 \\
2-t-Butyl-6-chloromethyl-[1,3]dioxan-4-one & C9H15CLO3 & 103 & 3.0 \\
Butane, 1,1'-oxybis- (CAS) n-Butyl ether & C8H18O & 57 & 3.3 \\
n Butyl ether & C8H18O & 57 & 19 \\
Nonane (CAS) n-Nonane & C9H20 & 43 & 5.6 \\
Propanoic acid, 2-methyl-, 2-methylpropyl ester & C8H16O2 & 71 & 0.8 \\
Propanoic acid, 2-methyl-, butyl ester & C8H16O2 & 43 & 0.3 \\
3-Hexen-2-one (CAS) 1-Butenyl methyl ketone & C6H10 & 43 & 1.0 \\
Pentane, 1-butoxy- & C9H20O & 57 & 1.6 \\
Decane (CAS) n-Decane & C10H22 & 43 & 3.2 \\
1-Limonene & C10H16 & 68 & 0.2 \\
Butane, 1,1-dibutoxy-(CAS) Lageracetal & C10H30O5Si5 & 57 & 0.3 \\
Cyclopentasiloxane, decamethyl- & C14H24O3Si2 & 73 & 0.2 \\
Benzeneacetic acid, 3-methoxy-.alpha.,4-bis[(tri & C14H30 & 163 & 0.2 \\
Tetradecane & C12H36O6Si6 & 57 & 0.3 \\
Cyclohexasiloxane, dodecamethyl- & C16H26O6Si2 & 73 & 0.3 \\
Trimethylsilyl 3-methoxy-2-(2-oxo-2-((trimethy & C16H34 & 73 & 0.4 \\
Hexadecane (CAS) n-Hexadecane & C12H36O5Si6 & 57 & 0.5 \\
1, 1, 3, 3, 5, 5, 7, 7, 9, 9, 11, 11-dodecamethylhexasilo & C22H40O4 & 73 & 0.1 \\
Oxalic acid, cyclohexylmethyl tridecyl ester & C19H40 & 97 & 0.4 \\
Nonadecane & C16H48O8Si8 & 57 & 0.3 \\
Cyclooctasiloxane, hexadecamethyl- & C7H34O2 & 73 & 0.1 \\
Hexadecanoic acid, methyl ester & C13H23NO3 & 74 & 0.3 \\
4-TERT-BUTYL-2-(1-METHYL-2-NITRO-ET & C16H48O6Si7 & 97 & 0.3 \\
Heptasiloxane, hexadecamethyl-(CAS) Hexadecamet & C16H48O6Si7 & 73 & 0.3 \\
Heptasiloxane, hexadecamethyl- & C20H42 & 73 & 0.3 \\
Heneicosane & C19H36O2 & 57 & 1.9 \\
9-Octadecenoic acid (Z)-, methyl ester & C16H48O6Si7 & 55 & 1.1 \\
Heptasiloxane, hexadecamethyl- & C24H72O12Si12 & 73 & 1.9 \\
TETRACOSAMETHYLCYCLODODECASIL & C20H45 & 73 & 1.7 \\
Hexacosane (CAS) n-Hexacosane & C36H8H74 & 57 & 1.9 \\
Tetracontane & C17H30O5S12 & 57 & 1.3 \\
Hexatriacontane & & 163 & 0.3 \\
Benzeneacetic acid, 3-methoxy-.alpha.,4-bis[(tri & &
\end{tabular}




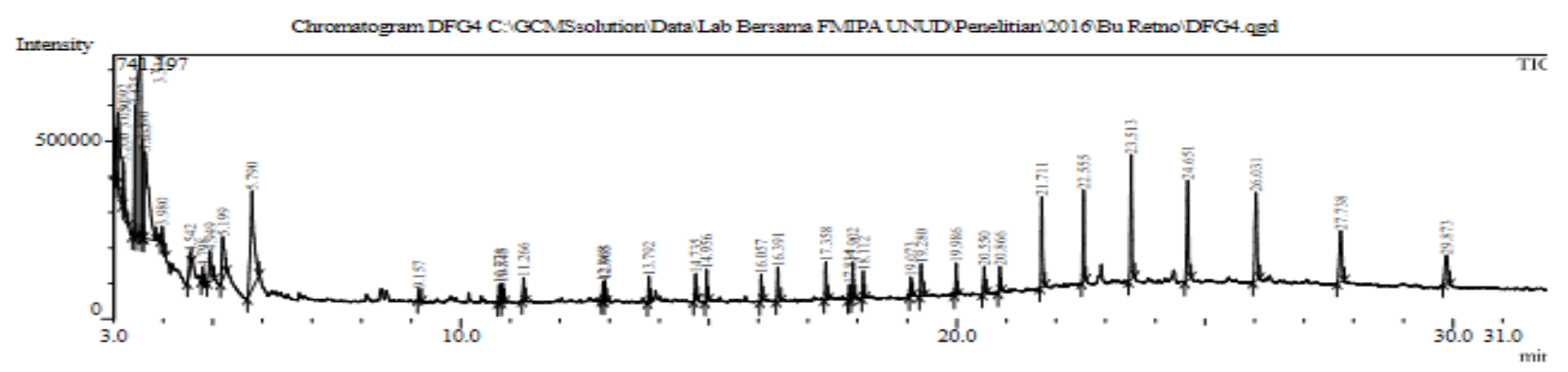

Figure 5. GC-MS chromatogram of n butanol extract of Streptomyces sp.Sp1

Table 5. Antimicrobial activities identified in the $\mathrm{n}$ butanol extract of Streptomyces sp.Sp1

\begin{tabular}{lcc}
\hline Name of the compound & Nature of compound & Activitya* $^{*}$ \\
\hline 3-Hexanone, 2-methyl & Organic compound & Antimicrobial \\
n Butyl ether & Organic compound & Antimicrobial \\
Hexacosane(CAS) n Hexacosane & Organic compound & Antimicrobial \\
Tetracontane & Organic compound & Antimicrobial \\
l-Limonene & Organic compound & Antimicrobial \\
Heneicosane & Organic compound & Antimicrobial \\
Decane (CAS) n-Decane & Organic compound & Antimicrobial \\
Hexadeconoic acid, methyl ester & Organic compound & Antimicrobial \\
Butane, 1, 1-dibutoxy & Organic compound & Antimicrobial \\
Nonane(CAS)n-Nonane & Organic compound & Antimicrobia \\
Benzeneacetic acid, 3-methoxy-.alpha.,4-bis[(tri & Organic compound &
\end{tabular}

*Source: Pubchem/open chemistry database

The chemical compounds which have antimicrobial properties identified in the $\mathrm{n}$ butanol extract of Streptomyces sp.Sp1. are 3-Hexanone, 2-methyl (43\%), n Butyl ether (19\%) Nonane (CAS) n-Nonane (5.6\%), Decane (CAS) n-Decane (3.2\%), Hexacosane(CAS) n-Hexacosane (1.9\%), Tetracontane (1.3\%), Heneicosane (1.9\%), Hexadeconoic acid, methyl ester (0.3\%), Butane,1,1-dibutoxy (0.3\%), and Limonene (0.3\%). Benzeneacetic acid, 3-methoxy-.alpha.,4-bis [(tri (0.3\%). The main chemical compounds (known as ketones group) is 3-Hexanone, 2-methyl (43\%).

Chemical compound 2-Methyl-3-hexanone is an organic compound belonging to the ketone group. The presence of a group of ketone compounds in Streptomyces, previously reported by Zothanpuia et al. (2017). In this study, Streptomyces cyaneofuscatus was isolated from fresh water sediments. Based on GCMS analysis, it was reported that the contents of the amines, ketones, aldehydes, and alkanes in the crude extract methanol from Streptomyces cyaneofuscatus were reported. Also carried out extract crude antibacterial tests, where the results have strong antibacterial activity against Gram positive bacteria, Gram negative bacteria, and pathogenic yeast. The results showed the highest activity against $E$. coli $(5.42 \mu \mathrm{g} / \mathrm{ml}$ to $15.89 \mu \mathrm{g} / \mathrm{ml})$ followed by C. albicans (4.12 $\mu \mathrm{g} / \mathrm{ml}$ to $12.6 \mu \mathrm{g} / \mathrm{ml})$, B. subtilis (3.96 $\mu \mathrm{g} / \mathrm{ml}$ to $11.2 \mu \mathrm{g} / \mathrm{ml})$, and P. aeruginosa $(3.17 \mu \mathrm{g} / \mathrm{ml}$ to $8.0 \mu \mathrm{g} /$ $\mathrm{ml})$.

The antibacterial activity of hexacosane compounds was tested by Rukaiyat et al. (2015). This compound is one of the active ingredients contained in the extract of the ethyl acetat plant stem Sanseveria liberica. The results of the study mentioned the presence of antibacterial activity against Klebsiela pnemoniae, Salmonela typhi, Mithecithinne staphaureus, and Proteus vulgaris. Dehjurian et al. (2017) identified the presence of hexacosane compounds in Cirsium arvense flower extract in Iran. Antibacterial activity is proven against $C$. arvense. Another study by Martins et al. (2015), identified this compound as one of the compounds contained in Kielmeyera coriacea which has antibacterial activity against aerobic and nonaerobic bacteria. Rajalakshmi and Mahesh (2014) also reported the content of Hexacosane (CAS) hexacosane in Aspergillus terreus extract which was shown to have antibacterial activity. 


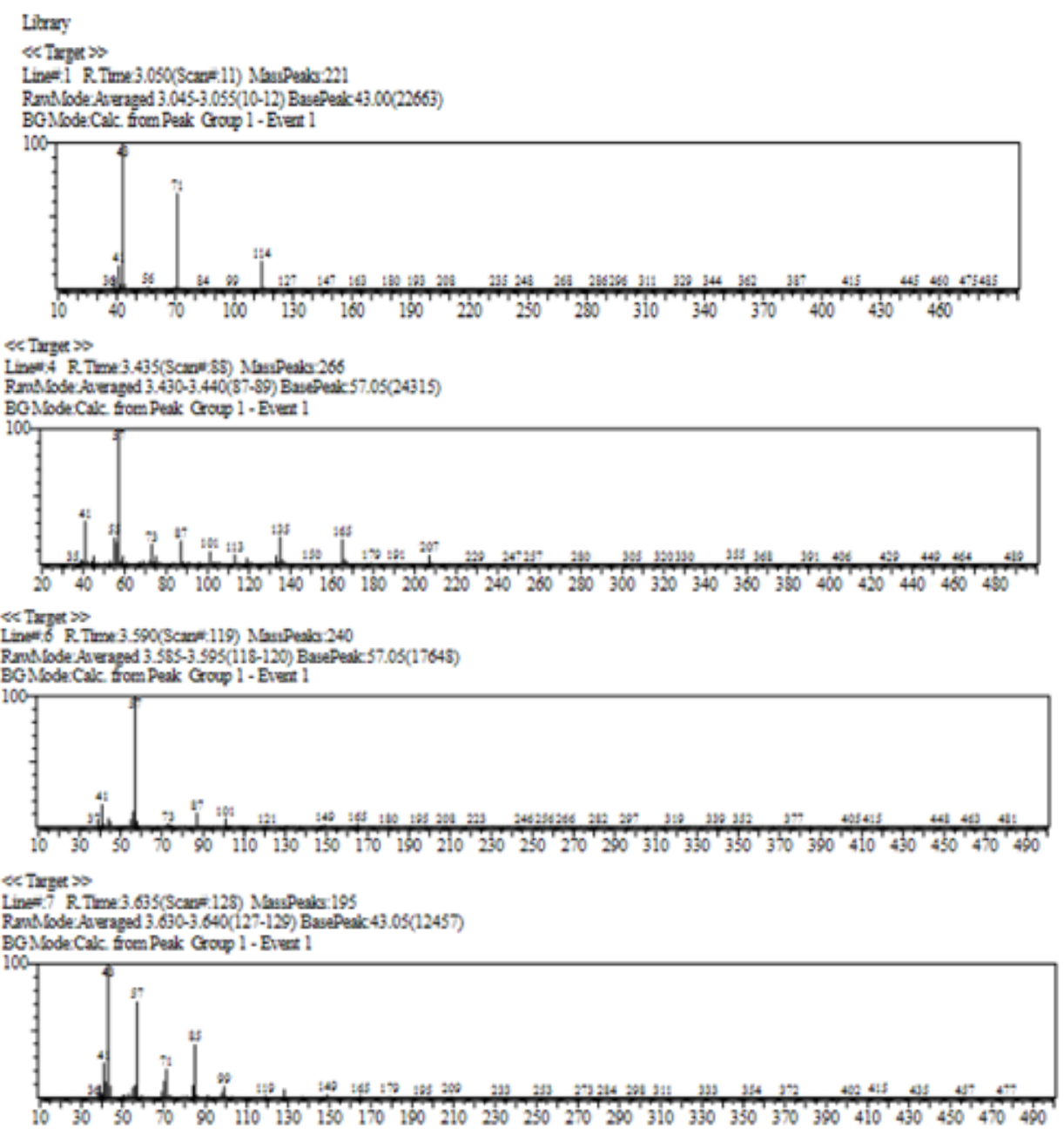

$\ll$ Trger $\gg$

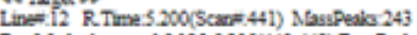

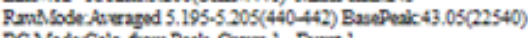

BGNode.Cale fom Pesk Growp 1 - Evern 1

${ }^{100} \mathrm{~T}$

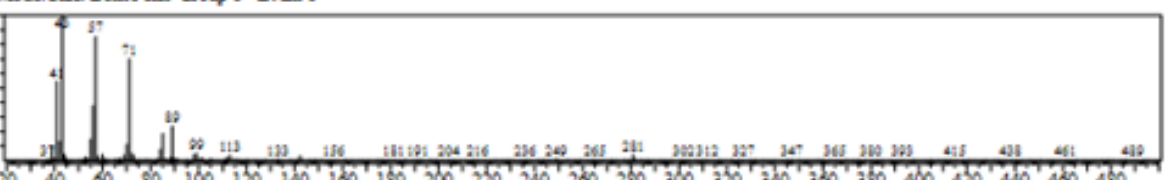

et Trager 80

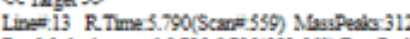

RanAlode:Auraged 5.785-5.795(358-560) BasePeak 68.05(35600)

BGModeCalc fom Peak Group 1 - Event 1

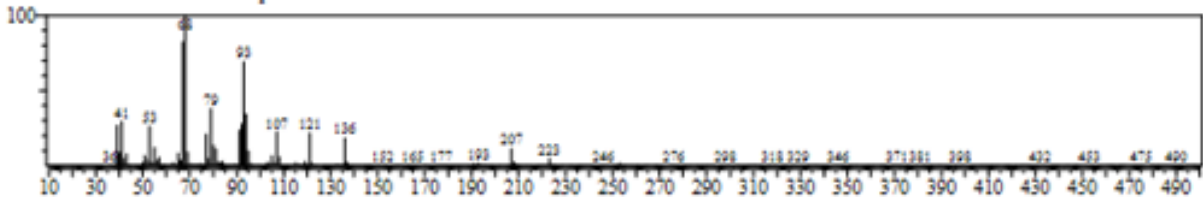

ec Target $>$

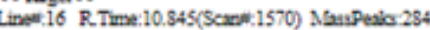

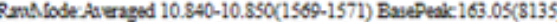

BOM Sode.Cale from Peak Croup 1 - Evert 1

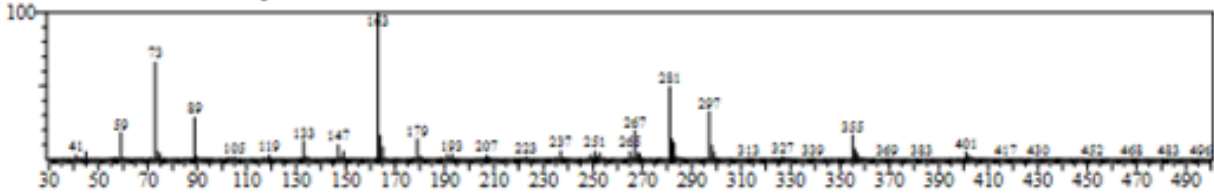

Figure 6. Spectrum of the 11 antimicrobial compounds detected in $\mathrm{n}$ butanol extract of Streptomyces sp.Sp1 


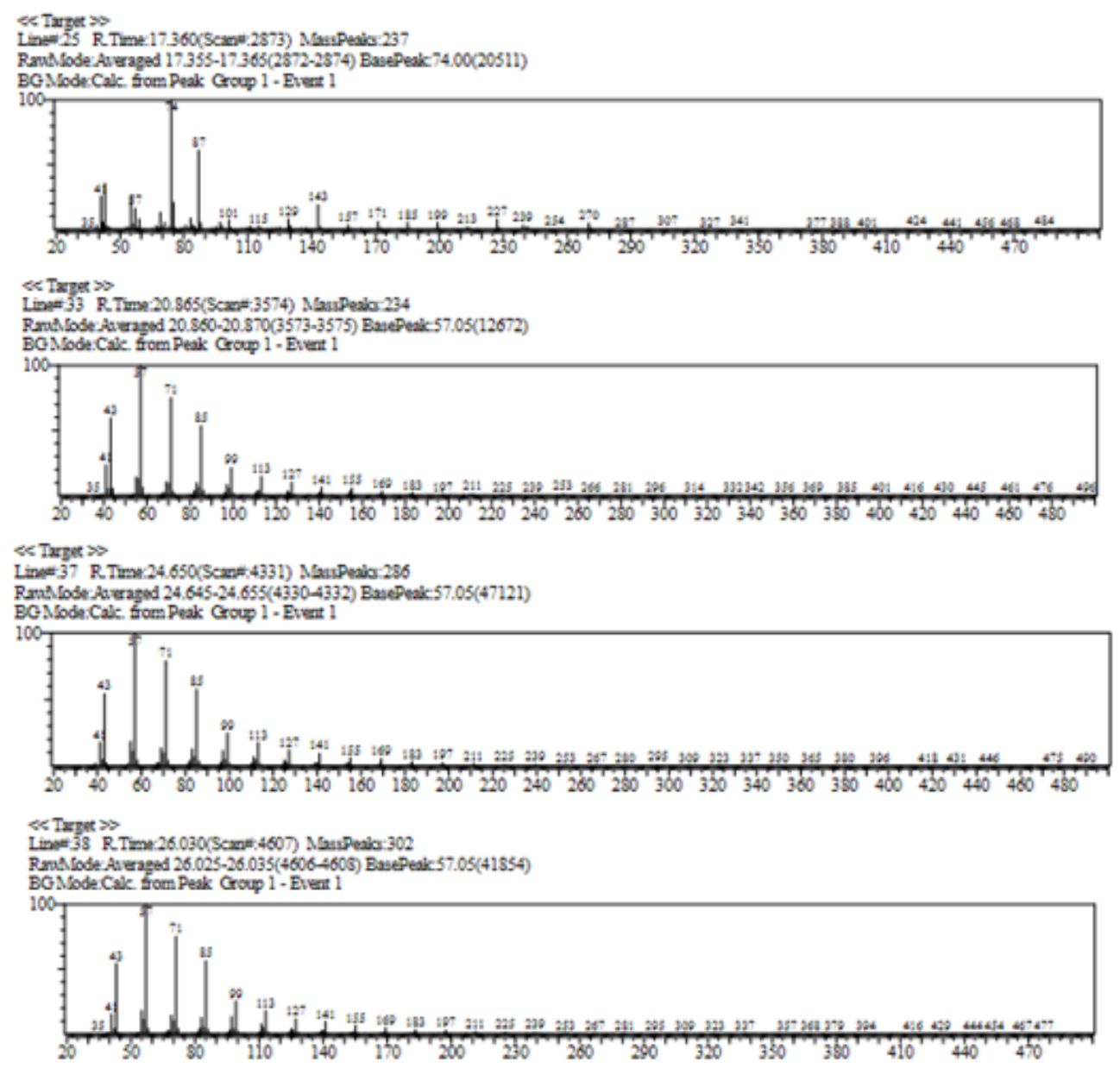

Figure 6. Continued

Tetracontane compounds are found as ingredients in various secondary metabolites which have antibacterial activity. Johnson et al. (2012) identified the presence of tetracontane, 3, 3, 2, 4-trimethyl from methanol extract of marine sponge Zygomycale sp. which was isolated from Kanyakumari beach (southeast coast of India). It was reported that the extract had antibacterial activity against Bacillus megaterium, Klebsiella pneumoniae, and Streptococcus pyogenes and antifungi against Aspergillus niger, Aspergillus fumigatus, Candida albicans, and Rhizomucor miehei. Tetracontane compounds in the form of tetracontane, 3,5,24-trimethyl- are identified as the content of chloroform extract of Hugonia mystax L. (Linaceae) by Vimalavady and Kavadul (2013), where the extract has antimicrobial activity, antifungal, and antioxidants.

Several studies have reported the activity of limonene compounds as antibacterial. Research by Haiyan et al. (2016) examined the antibacterial activity of limonene emulsions and acetone limonene solutions in three food pathogenic species. The tube dilution test in this study showed that limonene was effective for $Y$. enterocolitica and S. aureus, but was not effective for L. monocytogenes. Espina et al. (2013) reported the inhibitory of limonene mechanism for $E$. coli MC4100 by increasing permeability of the outer membrane and changing the structure of bacterial proteins. Obidi et al. (2013) tested the antimicrobial activity of citrus sinensis oil. The inhibitory effects were shown in all test microorganisms ( $S$. aureus 001, S. aureus ATCC 25923, Enterococcus feacalis 002 , E. feacalis ATCC 295212, P. aeruginosa 003, E. coli 004, E. coli ATCC 29522, C. albicans 010, and C. albicans ATCC 90028). GCMS results indicate the presence of D-limonane.

Ma et al.(2014) reported the presence of hyenicosane compounds as one of 87 compounds contained in tomato seed oil, which had antibacterial activity against S. aureus, E. coli, S. flexneri, and P. mirabilis. 
<smiles>CCCC(=O)C(C)C</smiles>

b<smiles>CCCCOCCCC</smiles>

e

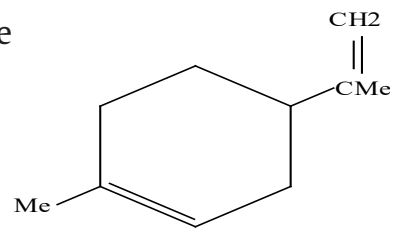

f

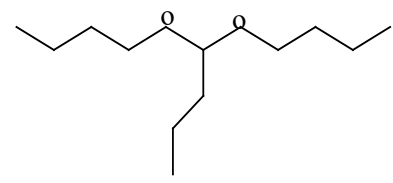

C

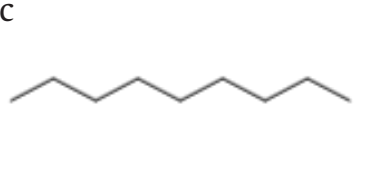

d<smiles>CCCCC(CC)CO</smiles>

$\mathrm{g}$

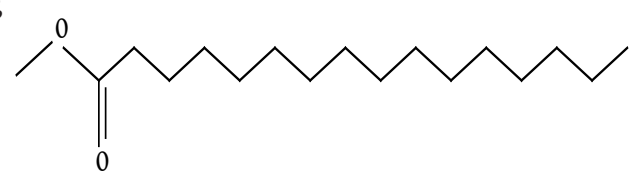

$\mathrm{h}$

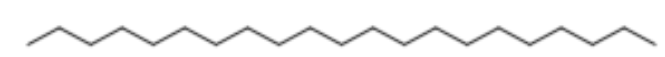

i

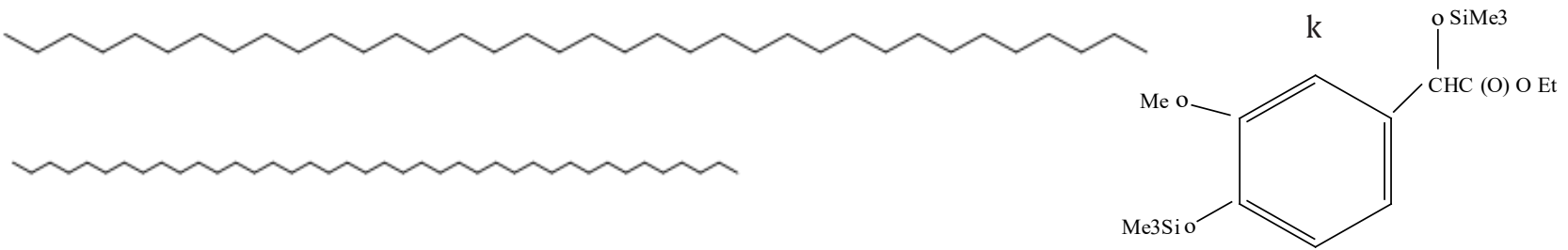

Figure 7. Structure of (a) 3-Hexanone, 2-methyl-, (b) n Butyl ether, (c) Nonane (CAS) n-Nonane, (d) Decane (CAS) n-Decane, (e) l-Limonene, (f) Butane, 1,1-dibutoxy-(CAS) Lageracetal, (g) Hexadecanoic acid, methyl ester, (h) Heneicosane,

(i) Hexacosane (CAS) n-Hexacosane, (j) Tetracontane, (k) Benzeneacetic acid, 3-methoxy-.alpha.,4-bis[(tri

Previous research by Dadasoglu et al.(2011) identified the presence of n-henecosane in Origanium extract (O. acutidens, $O$. rotundifolium, and 0 . vulgare) which is known to have antibacterial activity.

Research by Nahar et al. (2016) reported the content of decane as the main component of Trigonella foenumgraecum seed essential oil collected from Jessore Road in Bangladesh. The essential oils obtained were tested for antibacterial activity and showed antibacterial activity against Bacillus subtilis IFO 3026, Sarcina lutea IFO 3232, Xanthomonas campestris IAM 1671, Proteus vulgaris MTCC 321, and Pseudomonas denitrificans KACC 32026. Wang et al. (2013) identified decane compounds in the Bicyclo form decane, 2-methylene-5 (1-methylvinyl) -8-methyl-, 0.27 from Streptomyces alboflavus TD-1 which was reported to have antifungal activity against Fusarium moniliforme Sheldon, Aspergillus flavus, Aspergillus ochraceus, Aspergillus niger, and Penicillum citrinum in vitro.

Raningsih et al. (2015) identified the content of hexadeconoic acid, methyl ester in the filtrate of Nocardia sp. isolates. 1 which is reported to have antibacterial activity against Methicillin Resistance Staphylococcus aureus (MRSA). Another study by
Jaluldeen et al. (2015) also identified the presence of hexadeconoic acid, methyl ester compounds from crude extect ethyl acetat Streptomyces species which were isolated as endophytic bacteria in the rhizosphere of chili plants. Furthermore Nandhinietal. (2015) also reported that GC-MS analysis of extract $S$. cacaoi strain SU2 presence Heneiconsane, Dodecane, Eicosane, and Cetene that have antimcrobial activity to pathogenic bacteria and fungi.

As reported by El-Gendy et al. (2008) several substances namely 3,5 -Dichloro- 2pyridone, Benzeneacetic acid, Heptadecane, Phenol. 2.4-bis (1.1-dimethylethyl), Dodecanoic Acid Methyl, Ester, Hexadecanoic Acid Methyl Ester, 1-(+)-Ascorbic Acid 2.6 Dihexadecanoate were identified by GCMS characterization technique. These chemical compounds are the isolate substance derived from Streptomyces galbus TP2 and Streptomyces humidus, which are recognized as antifungal, and have a significant role in medical. Pramisandi et al. (2018) reported that Benzeneatisc acid is expected as precursor during Pinicillium chrysogenum fermentation to produce antibiotic penicillin $\mathrm{G}$.

Severeral Actinomycetes isolated from different soil are proven to inhibit pathogenic resistance bacteria 
such as Escherichia coli and Vancomycin-Resistant Enterococci. Furthermore, several substances such as 3,5 -Dichloro- 2 pyridone, Benzeneacetic acid, Heptadecane, Phenol. 2.4-bis(1.1-dimethylethyl), Dodecanoic Acid Methyl Ester, Hexadecanoic Acid MethylEster,1-(+)-Ascorbic Acid 2.6Dihexadecanoate were identified using the GC-MS characterization (Singh et al. 2012).

Moreover, Actinomycetes commonly synthetizes the Dodecanoic acid methyl ester and hexadecanoic acid methyl ester. The existence of those substances can be used as an indicator in Actinomycetes group classification (Susuki 1988). The mechanism of secondary metabolite of Actinomycetes occurs by damaging cell wall and obstructing cell division (Ambavane et al. 2014).

\section{Conclusion}

Streptomyces sp.Sp1 showed various bioactive properties, which highlighted its importance as potential biocontrol agents on Vibriosis desease. Hence, there were new bioactive compound in the extract, which might provide a basis for further development of novel compound from Streptomyces sp.Sp1. This also provided a new insight towards the development of good candidates for bioactive natural products.

\section{Conflict of Interests}

The authors declare that there is no conflict of interests regarding the publication of this paper.

\section{Reference}

Ambavane V et al. 2014. Caerulomycin A-An antifungal compound isolated from marine Actinomycetes. Advances in Microbiology 4:567-578.

Barrios-Gonzalez J et al. 2003. Microbial secondary metabolites production and strain improvement. Indian Journal of Biotechnology 2:322-333.

Bintari NWD et al. 2017. Streptomyces sp. as biocontrol of Vibriosis on Larvae of Macrobrachium rosenbergii (de Man) Prwans. J Biol Chem Research 34:238-248.

Dadasoglu F et al. 2011. Antibacterial activities of extracts and essential oils of three origanum species against plant pathogenic bacteria and their potential use as seed disinfectants. Journal of Plant Pathology 93:271-282.

Dehjurian A et al. 2017. Anti-bacterial activity of extract and the chemical composition of essential oils in Cirsium arvense from Iran, Journal of Essential Oil Bearing Plants 20:1162-1166.
El-Gendy MMA et al. 2008. Novel bioactive metabolites from a marine derived bacterium Nocardia sp. ALAA. J Antibiotica 61:379-386.

Espina L et al. 2013. Mechanism of bacterial inactivation by (+)-Limonene and its potential use in food preservation combined processes. PLOS ONE 8: e56769. doi:10.1371/journal.pone.0056769.

Gopalakrishnan S, Vadivel E. 2011. Gc-Ms analysis of some bioactive constituents of Mussaenda frondosa linn. International Journal of Pharma and Bio Sciences. 2:313-320.

Haiyan LU et al. 2016. Antibacterial effect of limonene on food-borne pathogens[J]. Journal of Zhejiang University (Agriculture and Life Sciences) 42:306-312.

Jalaluldeen AM et al. 2015. Growth characteristics and production of secondary metabolites from selected Streptomyces species isolated from the rhizosphere of chili plant. International Journal of Enhanced Research in Science Technology and Engineering 4:18.

Johnson JA et al. 2012. Antimicrobial screening and identification of bioactive compounds present in marine sponge Zygomycale sp. collected from kanyakumari coast. J Chem Biol Phys Sci 2:18421848.

Lowicki D, Huczyski A. 2013. Structure and antimicrobial properties of Monensin A and its derivatives: summary of the achievements. Biomed Research International 2:1-14.

Ma Y et al. 2014. Components, antioxidant and antibacterial activity of tomato seed oil. Food Science and Technology Research 20:1-6.

Marchesi JR et al. 1998. Design and evaluation of useful bacterium-spesific PCR primers that amplify genes coding for bacterial 16S rRNA. Appl Environ Microbiol 64:795-799.

Martins CM et al. 2015. Evidence-based complementary and alternative medicine. 2015. http://dx.doi.org/ 10.1155/2015/842047(https://www.hindawi.com/ journals/ecam/2015/842047/).

Nahar N et al. 2016. GC-MS analysis and antibacterial activity of Trigonella foenumgraecum against bacterial pathogens. Free Radicals and Antioxidants 6:109-114.

Nandhini US et al. 2015. Gass Chromatography-mass spectrometry analysis of bioactive constituents from the marine Streptomyces. Asian J of Pharmaceutical and Clinical Research 8:244-246.

Obidi OF et al. 2013. Antimicrobial activity of orange oil on selected pathogens. The International Journal of Biotechnology 2:113-122.

Oanh DTH et al. 2008. Characterization and Pathogenicity Studies on Vibrio Bacteria Isolated from Freshwater Prawn (Macrobrachium rosenbergii) Hatcheries. Available at : http://www.researchgate.net [Cited on 2015, September 2].

Patang. 2012. Pengaruh penggunaan berbagai antibiotik dan probiotik dengan dosis berbeda terhadap pertumbuhan dan kualitas air pada larva udang windu (Penaeus monodon (Fabricus)). Jurnal Agrisistem 80:77-78. 
Pramisandi A et al. 2012. Effect of Phenylacetic Acid Addition on Productivity of Penicillium chrysogenum in Penicillin G Production Using Pilot Scale Reactor. In: Int. Proceeding Conference. on Chemical and Material Engineering. Purwokerto: Diponegoro University Press. pp. 210-214.

Priyono SB et al. 2011. Pengaruh shelter terhadap perilaku dan pertumbuhan udang galah (Macrobrachium rosenbergii). J Fish Sci 8:78-85.

Rajalakshmi S, Mahesh N. 2014. Production and characterization of bioactive metabolites isolated from Aspergillus terreus in Rhizosphere soil of medicinal plants. Int J Curr Microbiol App Sci 3:784798.

Raningsih N et al. 2015. Antibacterial effect of Nocardia sp. against methicillin resistant staphylococcus aureus (MRSA). Int J Pure App Biosci 3:154-157.

Rukaiyat $\mathrm{M}$ et al. 2015. Antimicrobial activities of hexacosane isolated from Sanseveria liberica (Gerome and Labroy) plant. Medical Plant Research 3:120-125.

Sharon FB et al. 2013. Qualitative analysis of antimicrobial compound by high performance thin layer chromatography method. Asian J Pharm Clin Res 6:117-120.
Singh S et al. 2012. Isolation and partial characterization of Actinomycetes with antimicrobial activity against multidrug resistant bacteria. Asian Pacific Journal of Tropical Biomedicine 2:1147-1150.

Susuki K. 1988. Cellular fatty acid analysis in Actinomycete taxonomy. In: Proceeding of Seventh Int. Symp. on Biology of Actinomycetes. edition Okami Y, Верpu T, and Ogawa H. Tokyo: Japan Scientific Societies Press. pp. 251-256.

Vimaladavy A, Kadavul. 2013. Phytocomponents identified on the various extracts of stem of Hugonia mystax $\mathrm{L}$. (Linaceae). European Journal of Experimental Biology 3:73-80.

Wang C et al. 2013. Antifungal activity of volatile organic compounds from Streptomyces alboflavus TD-1. FEMS Microbiol Lett 341:45-51.

Zothanpuia et al.2017. Production of a potent antimicrobial compounds from Streptomyces cyaneofuscatus associated with fesh water sediment. Frontiers in Microbiology 8:1-13. 